\title{
Urban Addressing Practices and Geocoding Algorithm Validity in Developing Countries
}

\author{
Case of Casablanca City - Morocco
}

\author{
Mohamed El Imame MALAAININE ${ }^{1}$ \\ EHTP \\ Casablanca-Morocco
}

\author{
Hatim LECHGAR ${ }^{2}$ \\ FSAC-Hassan II University \\ Casablanca-Morocco
}

\begin{abstract}
Addressing systems have a key role in understanding and managing economic connections and social conditions, especially in urban territories. Developing countries need to learn from previous experiences and adapt solutions and techniques to their local contexts. A review of the world bank's experience in addressing cities in Africa during the 1990s provides valuable lessons. It provides an understanding of the operational issues and the key success factors of such operations. It also helps to understand the conceptual components of these systems and the efforts required to build them in the field before the creation of their IT infrastructure. An addressing experience from a private sector initiative in Casablanca-Morocco is also reviewed, where efforts concern the creation of a comprehensive database of addresses. The methods used to collect the data in the field are presented as well as the conceptual model for its integration. The validity of geocoding techniques, which represent the core computing tools of addressing systems, is discussed. In the Moroccan context, the official addressing rules follow Western models and standards, used by default in geocoding algorithms. The study of data collected in Casablanca, processed with GIS tools and algorithms, shows that the percentage of cases not respecting these rules is far from negligible. The analysis was particularly interested in the two main criteria of address numbers: "parity" and "respect of intervals", analyzed by street segment. Compliance with these conditions was only observed at about $53 \%$. It is then concluded that a geocoding system based on a linear model is not sufficiently validated in the Moroccan context.
\end{abstract}

Keywords-Addressing system; geocoding; Geographic Information System (GIS)

\section{INTRODUCTION}

Addresses are necessary data for citizens, administrations and companies. Through an address, a citizen can have access to several civil rights and public services; Administrations can efficiently manage their territories and companies can manage and optimize supply chains. It was once believed that about $80 \%$ of information, especially those used by local authorities, have a geographical component, related in a way or another to address locators [1], [2]. In the times of IoT (Internet of Things), it's hardly possible today to find data without spatial coordinates. While the latest geocoding literature deals with the latest techniques in the matter, such as machine learning [3] and deep learning particularly [4], the classical issues related to historical address structure and standardization remain relevant $[5,6]$. The general literature deals with geographic related applications in different countries such as in Australia [7], Brazil [8], China [9], Croatia [10], Cuba [11], Germany [12], India [13], Morocco [14], Quebec [15], South Africa [16], Turkey [17], etc. The applications based on address locators are more than ever evolving, and the need for reliable and accurate address systems has never been more. Unfortunately, while such systems have already reached the stage of maturity in developed parts of the world [18], [19], it remains a real issue in developing countries. However, it is there where it's the most needed, for basic applications, already discussed in research works in other contexts, such as health studies [20]-[22], politics [23], criminality [24], traffic accidents [25], emergency dispatching [26], etc.

In developing countries, the issue of addressing systems presents a big challenge, including norms on the field, availability and quality of the reference data and reliability of geocoding techniques. On the field, addresses numbers and streets names should be assigned according to logical and consistent methods. The quality of geocoding, which consists of transforming a given number of descriptive into a geographic position [27], will then depends on the quality of both the reference database of addresses and the used methods.

\section{REVIEW OF URBAN ADDRESSING IN AFRICA AND MOROCCO}

\section{A. The World Bank Experience in Africa}

The addressing process is a critical issue for the city. It is a challenge to be taken up by several stakeholders, including town planners who plan the base of future addresses, local authorities who assign formalized addresses, install and maintain signs for street names and squares, utilities who use addresses when providing services or billing, postal operators who deliver mail to an address, as well as residents who maintain the numbering plates of their buildings and can correct errors in their addresses.

This complex operation includes the formalization of the rules of reference for the addressing process. It consists of creating and updating standardized addresses in the city. The two important operations carried out on the field are: the naming of the streets and the numbering of the buildings. 
TABLE I. The TeChNicAl FEATURES OF AdDRESSING PraCtices IN SOME AFricAN COUNTRIES

\begin{tabular}{|l|l|l|l|l|}
\hline & Burkina-Faso & Cameroun & Guinea & Niger \\
\hline Division & sectors & zones & municipalities & neighborhood groups \\
\hline Street codification & sector \& order number & zone \& order number & $\begin{array}{l}\text { neighborhood initials \& } \\
\text { order number }\end{array}$ & neighborhood initials \& order number \\
\hline Numbering doorways & metric and alternating & metric and alternating & metric and alternating & metric and alternating \\
\cline { 1 - 4 } street signs supply & $\begin{array}{l}\text { international bidding } \\
\text { process }\end{array}$ & $\begin{array}{l}\text { local firm } \\
\text { (bidding process) }\end{array}$ & $\begin{array}{l}\text { local firm } \\
\text { (bidding process) }\end{array}$ & international bidding process \\
\hline \multirow{2}{*}{ Street sign installation } & small local companies & $\begin{array}{l}\text { municipal employees } \\
\text { \& } \\
\text { NGO survey takers }\end{array}$ & $\begin{array}{l}\text { addressing unit and } \\
\text { municipal technical } \\
\text { departments }\end{array}$ & $\begin{array}{l}\text { local company under supervision of } \\
\text { addressing unit }\end{array}$ \\
\cline { 2 - 4 } $\begin{array}{l}\text { Surveys and number } \\
\text { assignment }\end{array}$ & addressing unit & addressing unit \\
\hline \multirow{2}{*}{ Survey data } & $\begin{array}{l}\text { address } \\
\text { occupant's name, plot } \\
\text { use category, and } \\
\text { cadastral references }\end{array}$ & $\begin{array}{l}\text { address, occupant's } \\
\text { name, plot use category, } \\
\text { cadastral references, } \\
\text { type of activity }\end{array}$ & $\begin{array}{l}\text { address, occupant's name, } \\
\text { plot use category, water } \\
\text { and electricity meter } \\
\text { numbers. }\end{array}$ & $\begin{array}{l}\text { address, occupant's name, plot use } \\
\text { category, the cadastral reference, whether } \\
\text { or not electricity and water are } \\
\text { available, and information on streets }\end{array}$ \\
\hline \multirow{2}{*}{ Address directory } & $\begin{array}{l}\text { specialized software } \\
\text { program }\end{array}$ & $\begin{array}{l}\text { addressing Software } \\
\text { developed locally }\end{array}$ & $\begin{array}{l}\text { special software program } \\
\text { address management software program }\end{array}$ \\
\hline
\end{tabular}

The World Bank carried out several addressing experiments during the 1990s, in different African cities [28]. Table I presents an overview of the technical features of addressing practices in Burkina-Faso (Ouagadougou and Bobo-Dioulasso), Cameroun (Yaoundé and Douala), Guinea (Conakry) and Niger (Niamey). The world bank's financially and technically supported addressing projects extended to several other African cities in Mali, Mauritania, Mozambique, Senegal, Benin, Rwanda, Djibouti, Togo, and Côte d'Ivoire (Ivory Coast). Fig. 1 shows the concerned countries.

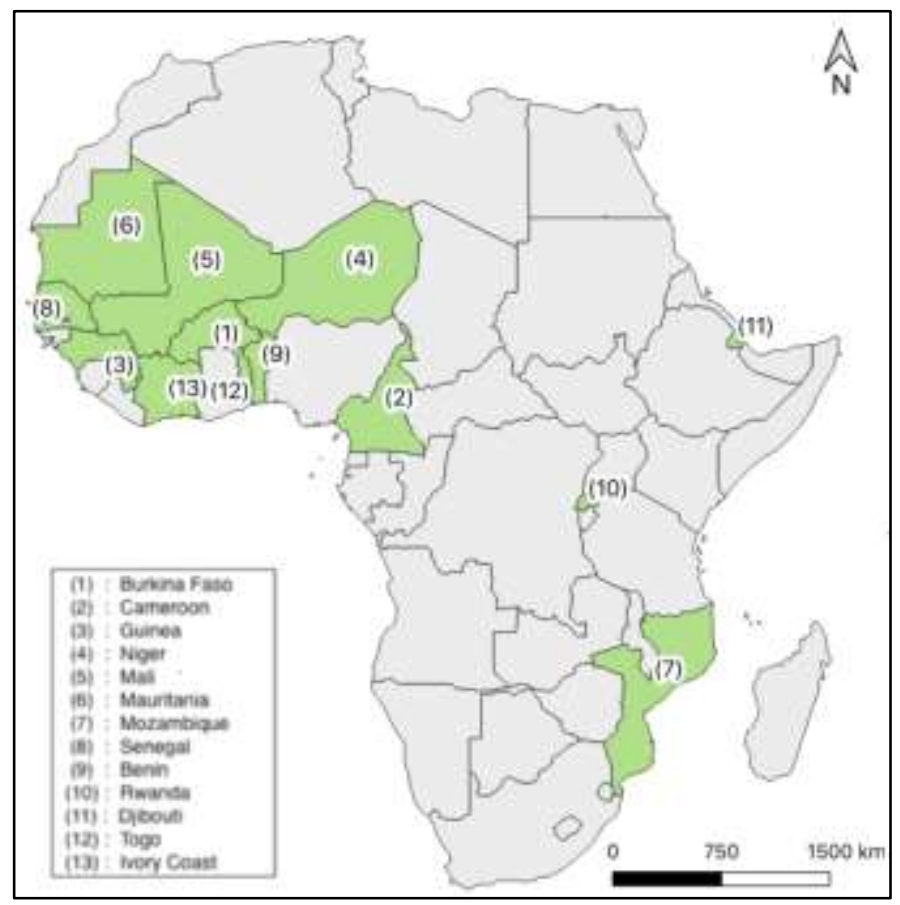

Fig. 1. Addressing Projects Countries, Supported by the World Bank during the 1990s.
The World Bank's recommendations for addressing operations are based on the observation that it is almost impossible to name all streets that addressing operations are first of all - a municipal action and that addresses are to be defined in relation to the streets and not in relation to the blocks.

The key success factors for successful addressing operations that were concluded from these experiences are: organization and motivation of the addressing unit; the involvement of the municipalities, decision-makers and technical services (which must have the necessary means and skills); financial efficiency during the project (while having good control); the simplicity of the database and the software developed to facilitate transition after the project phase (in particular to ensure that addresses are updated); controlling the scope of the project (concentration of efforts on the pure and simple objective of addressing); good coordination with stakeholders, in particular utilities and the post offices.

The main indicators that were used to assess the outcome of these projects are: the budget of the operation, the number of street signs installed, the number of buildings "addressed" (percentage of households concerned) and cost per capita and per addressed door. In the long term, the growth rates of local services such as tax collection and postal services should confirm the success of these operations.

\section{B. Private Sector Initiative in Casablanca-Morocco}

The first known addressing project, aiming to create a comprehensive database of addresses, inventorying all address locators of a major Moroccan city was initiated in Casablanca city in the late 2000s. It is the private company, insuring the delegated management of water and electricity utilities in the Grand Casablanca that was behind this initiative. In the absence of providers of such important data, critical for its operations, the company had to collect more than 400000 address locators. Fig. 2 shows the projects area. 


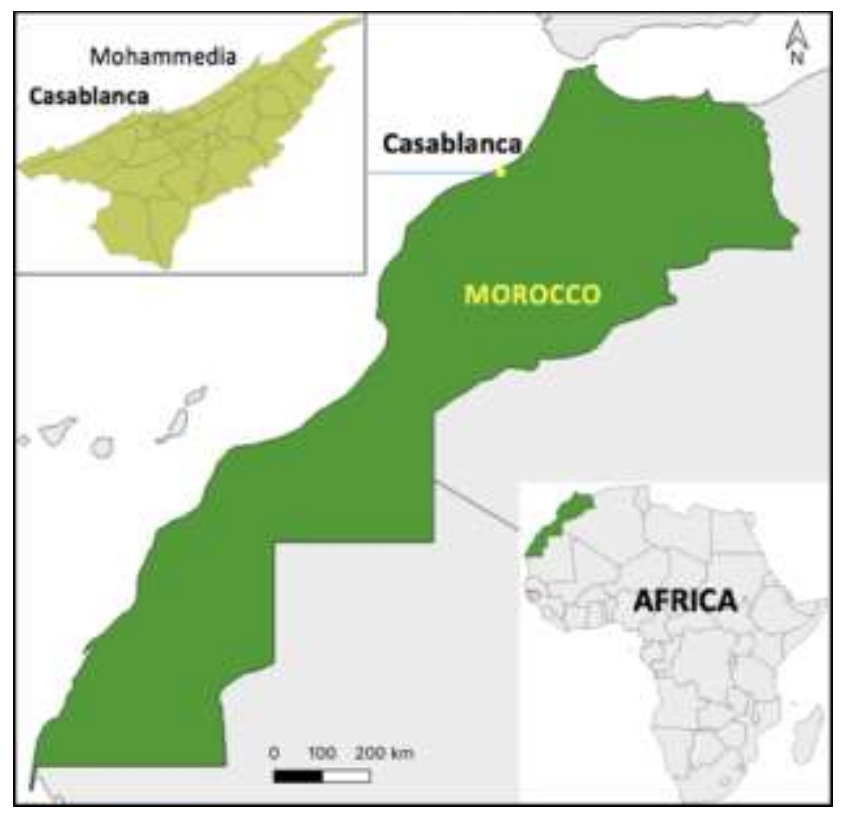

Fig. 2. Projects Area of the Private Sector Initiative in Casablanca-Morocco.

After planning and reference data acquisition, such as streets and necessary base map data, 200 operators were sent to the field, equipped with 3500 printed plans in total. Each map concerns a specific sector and contains the reference data necessary to recognize address locators to collect: streets, plots, remarkable places, neighborhoods and sector limits [29].

The targeted area is divided into sectors, well known and mastered by the field operators. Each sector is printed in suitable format map, with the sector reference included. Once the field survey is performed, with both positions and descriptive information required for the matching with the company's operational database, the maps are handed to the back-office for filling the project database. A sub set of these maps is then used for quality control. All maps are in the end scanned and archived.

\section{Discussion of Addressing Field Operations Practices}

In order to create an addressing database (as in the case of the private initiative in Casablanca), or to prepare an inventory to improve addressing in the city (as in the case of initiatives assisted by the World Bank in Africa), complex field surveys operations are required. Two missions can be distinguished, to be carried out successively, since the first one makes it possible to better prepare the second one by providing its necessary reference data. First, mission I, the survey of streets and their signs, then mission II, the survey of the numbering of buildings.

Before starting the field operations, data model conception of information to be collected is necessary. Table II shows the key data for the two missions.

Once identified, these data should be integrated into a larger addressing data model, such as the one presented in Fig. 3 using the UML formalism.

1) Mission I: Streets survey: Given that the area to be covered is often very large, (for instance, more than $1220 \mathrm{~km} 2$ in the case of the Casablanca project), the field surveys must be organized by geographic elements that can be mastered and easily navigable, in order to allow fluidity of operations on the field. All data that can be acquired before the field mission, such as the streets plots, must be integrated beforehand, so that the strict minimum data should be gathered from the field.

The choice of street segments as survey basic elements has the following advantages: allow the control of the total coverage of the study area; optimize the circuits of passage in the field; allow the allocation of different sections, belonging to the same street, to several operators (which corresponds to the logic of the administrative division of cities); gather information that may change from one street segment to another, such as width; prepare for the city signs plan which is designed by segment of street.

2) Mission II: Numbering survey: For the same reason of optimization, the use of streets' segments as basic elements for organizing this second mission remains relevant. It would also be possible to combine this logic with an administrative or business division of the project area, in order to define circuits that are easily recognizable by the field operators.

Another reason to consider the streets segments for this second mission too would be to anticipate the preparation of basic data for the development of a geocoder, the quality of which improves while using street segments instead of streets.

TABLE II. KeY AdDRESSING DATA

\begin{tabular}{|l|l|l|}
\hline & Entity & Key attributes \\
\hline \multirow{2}{*}{\begin{tabular}{l} 
Mission \\
\cline { 2 - 3 }
\end{tabular}} & $\begin{array}{l}\text { Streets } \\
\text { Streets } \\
\text { signs }\end{array}$ & $\begin{array}{l}\text { Geometry (linear), name, type, width, length } \\
\text { condition (Point), type (plate or panel), text, }\end{array}$ \\
\hline $\begin{array}{l}\text { Mission } \\
\text { II }\end{array}$ & $\begin{array}{l}\text { Address } \\
\text { locations }\end{array}$ & $\begin{array}{l}\text { Geometry (Point), Number in the road, Name of the } \\
\text { road, Name of building), Type (Building, villa, } \\
\text { house...), Use (Residential, commercial, industrial, } \\
\text { mixed), Activities }\end{array}$ \\
\hline
\end{tabular}

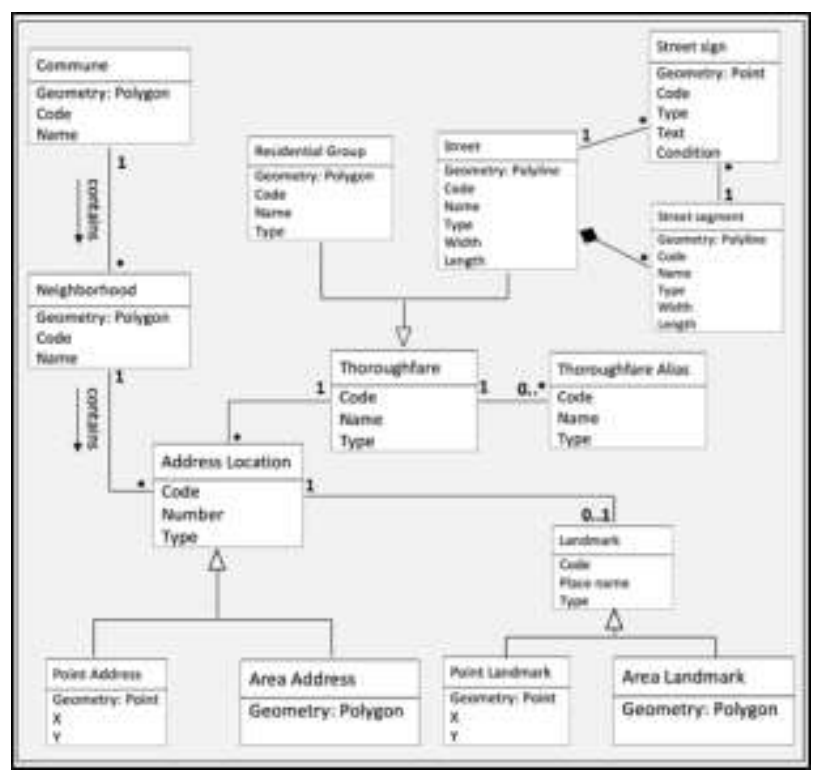

Fig. 3. UML Addressing Data Model. 


\section{REVIEW OF GEOCODING TECHNIQUES AND CONDITIONS}

\section{A. Geocoding Techniques}

The principle of geocoding methods is to compare a list of descriptive address elements with a well-structured reference database. This operation is done in three steps that represent the general geocoding algorithm, which are well documented in the literature [30]-[32], shown in the Fig. 4.

The Geocoding process manipulates "Input data" in order to get "Output data" through a "Matching algorithms" using a structured "Reference database"; those are the four parameters of geocoding and here after their dynamics. In Input, data to geocode is introduced, in form of a list of descriptions such as a postal address details. In Output, a georeferenced data is returned, with the geometry that is supported by the processing algorithm. It is often a two-dimensional point, but it can also be another form of complex data such as 3D objects [33]. It is the matching algorithm that decides of the corresponding result, based on the input data, the reference data and matching rules. This is why research works focuses especially on matching algorithms.

When all the address points' locations are available, in the case of a comprehensive reference database, the matching operation becomes quite evident. A simple search request is enough to find the exact coordinates to return. On the other hand, in the case of linear alternating numbering model, the returned position is rather calculated. It is an interpolated position based on the elements available in the linear referencing database, notably in the streets and street segments, such as intervals and parity of numbers on each side of the streets segment [34], [35].

\section{B. Geocoding Algorithm Preconditions}

The geocoding algorithms, in the case of linear alternating numbering model widely prevailing, begins with determining the street segment which corresponds to the descriptive list of the searched location. This first step uses the address numbers interval in the attributes of the street segments. Once the segment is determined, the address side (right or left) is concluded from the parity types (odd or even) of the numbers on either side of the segment, and the parity of the number in the searched address location. The exact position on the corresponding side is then calculated. Other parameters such as distance and angle from the segment and offsets from its ends can fine-tune the accuracy of the estimated position.

Other data can also improve this accuracy, such as information on the number of buildings on each side and their geographical distribution [36],[37].

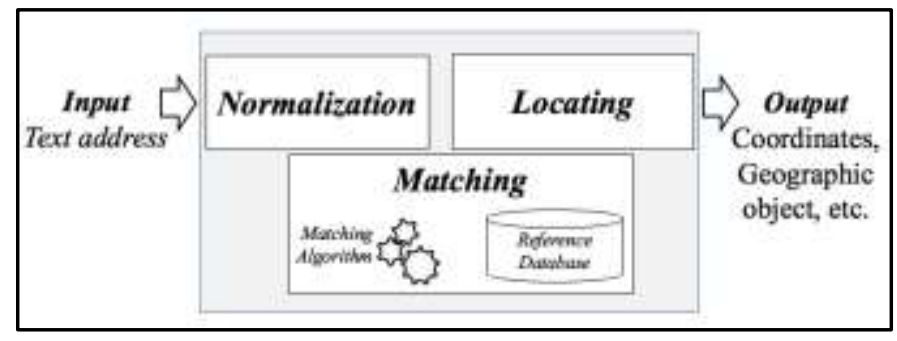

Fig. 4. Geocoding General Process.

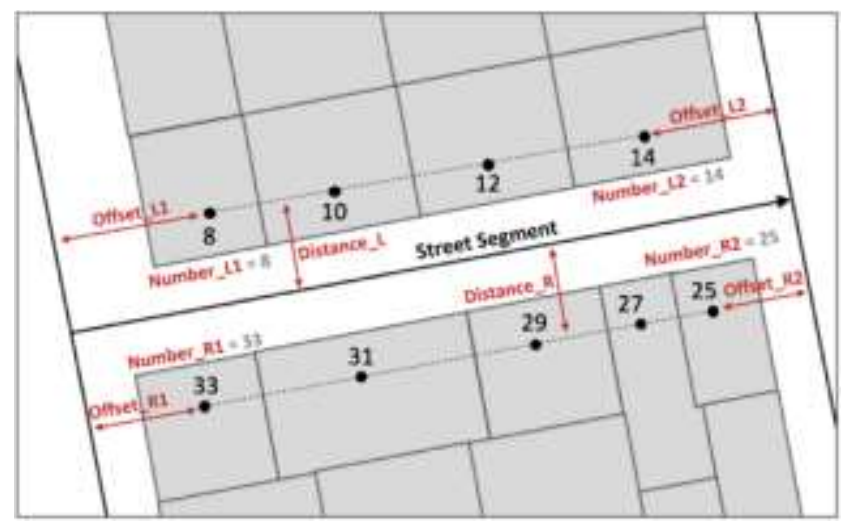

Fig. 5. Geocoding Parameters Overiew.

Fig. 5 shows an example of Geocoding parameters in the case of linear alternating numbering, where Number_L1 and Number_L2 are first and last numbers on the left side; Number_R1 and Number_R2 are first and last numbers on the right side; Offset_L1, Offset_L2, Offset_R1 and Offset_R2 are the offsets from the left and right ends; Distance_L and Distance_R are the distances from the segment.

For the geocoding algorithm to be effective, two main prerequisites must be satisfied by addresses in the field: consistent number intervals per street segment and consistent parity on each side. The uniformity of the distribution of buildings on each side of the street segment improves the accuracy of the calculated position.

\section{METHODOLOGY}

In this section, the evaluation of the main prerequisites of geocoding is studied, notably address numbers parity and intervals, in the city of Casablanca.

\section{A. Study Area and used Data}

The main data used are the streets shapefile and address locators collected in the field as part of the private initiative project in Casablanca, presented in Section II. This database of 63,833 address locators of the communes of: Anfa, Maarif, Mers Sultan, Sidi Belyout and El Fida, represents approximately $15 \%$ of the total number of address locators in Grand Casablanca (Fig. 6).

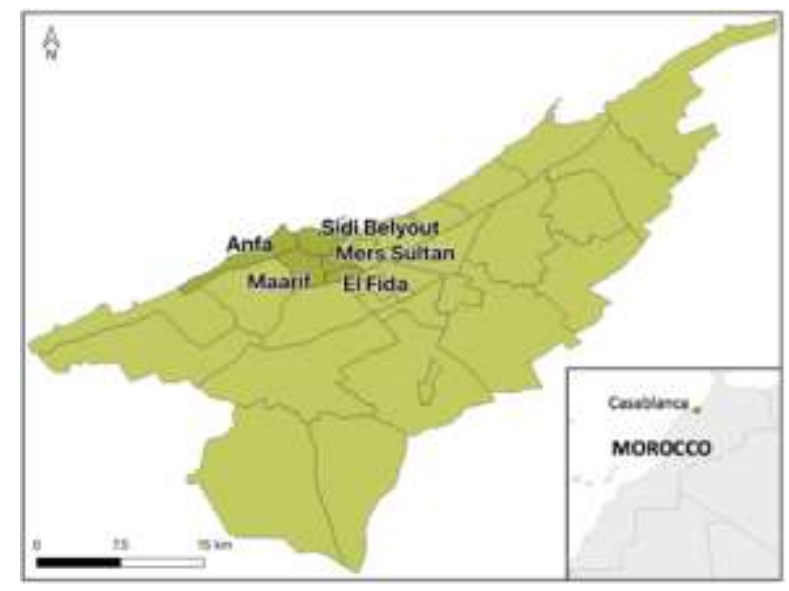

Fig. 6. Case Study Area. 
From the streets shapefile, using a GIS software, street segments are generated. Then, for each address point, the relative position (left or right) with respect to its street segment is calculated. Finally, for each street segment, the geocoding parameters are calculated.

\section{B. Geocoding Preconditions Analysis Method}

To assess the validity of the main prerequisites of geocoding presented previously, two main questions need to be answered: For what percentage, the numbers of address locators are consistent with the parity condition of their side of the street segment? And what percentage of the address locators' numbers fall within the range of the numbers' interval on their side of the street segment? let:

For address locators belonging to a given street segment $\mathrm{S}$,

- PS (OL): The percentage of address locators with an Odd number that are on the Left side of the street segment.

- PS (OR): The percentage of address locators with an Odd number that are on the Right side of the street segment.

- PS (EL): The percentage of address locators with an Even number that are on the Left side of the street segment.

- PS (ER): The percentage of address locators with an Even number that are on the Right side of the street segment.

For an odd number and an even number belonging to a street segment $\mathrm{S}$, the probability that the even number is on the left side and the odd number is on the right is:

$\mathrm{PS}(\mathrm{EL}$ and $\mathrm{OR})=\mathrm{P}(\mathrm{EL}) \times \mathrm{P}(\mathrm{OR})$

Similarly:

$\mathrm{PS}(\mathrm{ER}$ and $\mathrm{OL})=\mathrm{P}(\mathrm{EL}) \times \mathrm{P}(\mathrm{OR})$

Since the the street segments that meet the parity condition are those that have all odd numbers on one side and all even numbers on the other side, these streets are those verifying:

$\mathrm{P}(\mathrm{EL}$ and $\mathrm{OR})=1$ or $\mathrm{P}(\mathrm{ER}$ and $\mathrm{OL})=1$

Among the address locators belonging to such a street segment, those which meet the number range condition are those whose numbers are exclusively within the range of this street segment (taking into account all segments belonging to the address's street).

\section{RESUlTS DisCUSSION AND CONCLUSION}

Table III shows that $87 \%$ of street segments verify (3), then fulfil the first condition: the consistency of the parity of the address numbers. The percentage of address locators belonging to these streets segments is $83 \%$ as shown in Table IV. Among these points, $61 \%$ have a number that belongs to one and only one range of segment numbers, for this also meet the second condition: the consistency of the rages of numbers (Table V).
TABLE III. SEGMENTS PARITY CONSISTENCY

\begin{tabular}{|l|l|l|}
\hline Case & Number of segments & Percentage \\
\hline $\begin{array}{l}\text { Even numbers on the right } \\
\text { \& Odd numbers on the left }\end{array}$ & 3,472 & $47 \%$ \\
\hline $\begin{array}{l}\text { Even numbers on the left } \\
\text { \& Odd numbers on the right }\end{array}$ & 2,885 & $39 \%$ \\
\hline $\begin{array}{l}\text { Even numbers on one side } \\
\text { \& odd numbers on the other }\end{array}$ & 6,357 & $\mathbf{8 7 \%}$ \\
\hline All street segments & 7,325 & $100 \%$ \\
\hline
\end{tabular}

TABLE IV. ADDRESS LOCATORS PARITY CONSISTENCY

\begin{tabular}{|l|l|l|}
\hline Case & Number of points & Percentage \\
\hline $\begin{array}{l}\text { Even numbers on the right } \\
\text { \& Odd numbers on the left }\end{array}$ & 27,062 & $45 \%$ \\
\hline $\begin{array}{l}\text { Even numbers on the left } \\
\text { \& Odd numbers on the right }\end{array}$ & 22,269 & $37 \%$ \\
\hline $\begin{array}{l}\text { Even numbers on one side } \\
\text { \& odd numbers on the other }\end{array}$ & 49,331 & $\mathbf{8 3 \%}$ \\
\hline $\begin{array}{l}\text { All Points (having a street as } \\
\text { toponym) }\end{array}$ & 59,741 & $100 \%$ \\
\hline
\end{tabular}

TABLE V. ADDRESS LOCATORS INTERVALS CONSISTENCY

\begin{tabular}{|l|l|l|}
\hline Case & Number of points & Percentage \\
\hline In one interval & 29,892 & $\mathbf{6 1 \%}$ \\
\hline In many intervals & 19,439 & $39 \%$ \\
\hline All points (parity consistent) & 49,331 & $100 \%$ \\
\hline
\end{tabular}

If we consider all the address locators with a street toponym in the study area, the percentage of compliance with the two rules is around 53\%. This percentage drops to only $47 \%$, if we consider all address locators, regardless of the types of toponyms, since $6 \%$ of address locators are not linked to a street toponym.

These results indicate that the conditions necessary for the use of standard geocoding, based on linear alternating numbering model according to Western standards, are not met in the Moroccan case. Thus, the establishment of a national addressing system based on geocoding could not ensure the quality necessary for the applications which depend on it.

This problem can be explained by the lack of application of addressing standards in the field: temporary addresses allocated to housing development projects that become permanent, streets that are not assigned official names for long periods of time (years in some cases), addressing services which lack resources and coordination in cities experiencing a rapid expansion which further complicates the situation.

That said, the bulk of the problem is first organizational before it is technical. So, in order to be able to set up a reliable reference addressing system, urgent solutions must be proposed and others must be established over time.

Thus, in the short term, addressing campaigns like those of the World Bank in Africa must be carried out to overcome the lack of address references in the field and to promote the addressing of cities. Such campaigns will also make it possible to have up-to-date and more general data on the addressing situation throughout the country, the latest data available only 
concerning the city of Casablanca and already dating back almost ten years. Addressing information systems must be built around comprehensive databases and not on interpolation algorithms as long as the addresses in the field does not comply with the standards.

Over time, the addressing standards themselves as well as the address attribution procedures must be improved. They must be integrated into the urbanization and management processes of the city since early stages in order to avoid temporary, non-compliant solutions that last. This surely cannot be done without a good governance, led by specialized organizations which collaborate with businesses and research institutions.

\section{REFERENCES}

[1] Davis, C. A., \& Fonseca, F. T. (1993, July). Address base creation using raster/vector integra-tion. In Papers from the Annual Conference-Urban and Regional Information Systems Association (PP. 39-39). Urisa Urban and Regional Information Systems.

[2] Eichelberger, P. (1993). The importance of addresses-the locus of gis. In Papers from the Annual Conference-Urban and Regional Information Systems Association (PP. 212-212). Urisa Urban and Regional Information Systems.

[3] Lee, K., Claridades, A. R. C., \& Lee, J. (2020). Improving a StreetBased Geocoding Algorithm Using Machine Learning Techniques. Applied Sciences, 10(16), 5628.

[4] Yin, Z., Ma, A., \& Goldberg, D. W. (2019). A deep learning approach for rooftop ge-ocoding. Transactions in GIS, 23(3), 495-514.

[5] Kirielle, N., Christen, P., \& Ranbaduge, T. (2019, December). Outlier Detection Based Accurate Geocoding of Historical Addresses. In Australasian Conference on Data Mining (pp. 41-53). Springer, Singapore.

[6] Matci, D. K., \& Avdan, U. (2018). Address standardization using the natural language process for improving geocoding results. Computers, Environment and Urban Systems, 70, 1-8.

[7] Christen, P., Churches, T., \& Willmore, A. (2004, December). A probabilistic geocoding system based on a national address file. In Proceedings of the 3rd Australasian Data Mining Confer-ence, Cairns.

[8] Davis Jr, C. A., \& de Alencar, R. O. (2011). Evaluation of the quality of an online geocoding resource in the context of a large Brazilian city. Transactions in GIS, 15(6), 851-868.

[9] Tian, Q., Ren, F., Hu, T., Liu, J., Li, R., \& Du, Q. (2016). Using an optimized Chinese address matching method to develop a geocoding service: a case study of Shenzhen, China. ISPRS In-ternational Journal of Geo-Information, 5(5), 65.

[10] Cetl, V., Kliment, T., \& Jogun, T. (2018). A comparison of address geocoding techniques-case study of the city of Zagreb, Croatia. Survey Review, 50(359), 97-106.

[11] de Armas García, C. J., \& Cruz Gutiérrez, A. A. (2013). Deployment of a National Geocoding Service: Cuban Experience. Journal of the Urban \& Regional Information Systems Associa-tion, 25(1).

[12] Ahlers, D., \& Boll, S. (2009). On the accuracy of online geocoders. Geoinformatik 2009.

[13] Chatterjee, A., Anjaria, J., Roy, S., Ganguli, A., \& Seal, K. (2016, October). SAGEL: smart ad-dress geocoding engine for supply-chain logistics. In Proceedings of the 24th ACM SIGSPATIAL International Conference on Advances in Geographic Information Systems (pp. 1-10).

[14] Malaainine, M. E. I., Rhinane, H., Baidder, L., \& Lechgar, H. (2013). Omt-g modeling and cloud implementation of a reference database of addressing in Morocco.

[15] Burns, S., Miranda-Moreno, L., Stipancic, J., Saunier, N., \& Ismail, K. (2014). Accessible and practical geocoding method for traffic collision record mapping: Quebec, Canada, case study. Transportation research record, 2460(1), 39-46.

[16] Coetzee, S., \& Cooper, A. K. (2007). What is an address in South Africa?. South African Journal of Science, 103(11-12), 449-458.
[17] Yildirim, V., Yomralioglu, T., Nisanci, R., \& Inan, H. (2014, June). Turkish street addressing system and geocoding challenges. In Proceedings of the Institution of Civil Engi-neers-Municipal Engineer (Vol. 167, No. 2, pp. 99-107). Thomas Telford Ltd.

[18] Martin, D. (1999). Spatial representation: the social scientist's perspective. Geographical in-formation systems, 1, 71-80.

[19] Boscoe, F. P., Ward, M. H., \& Reynolds, P. (2004). Current practices in spatial analysis of can-cer data: data characteristics and data sources for geographic studies of cancer. International journal of health geographics, $3(1), 28$.

[20] Cromley, E. K. (2019). Using GIS to address epidemiologic research questions. Current Epi-demiology Reports, 6(2), 162-173.

[21] Boulos, M. N. K. (2004). Towards evidence-based, GIS-driven national spatial health infor-mation infrastructure and surveillance services in the United Kingdom. International Journal of Health Geographics, 3(1), 1.

[22] Rushton, G., Armstrong, M. P., Gittler, J., Greene, B. R., Pavlik, C. E., West, M. M., \& Zimmer-man, D. L. (2006). Geocoding in cancer research: a review. American journal of preventive medicine, 30(2), S16-S24.

[23] Haspel, M., \& Knotts, H. G. (2005). Location, location, location: Precinct placement and the costs of voting. The Journal of Politics, 67(2), 560-573.

[24] Ratcliffe, J. H. (2001). On the accuracy of TIGER-type geocoded address data in relation to ca-dastral and census areal units. International Journal of Geographical Information Sci-ence, 15(5), 473-485.

[25] Qin, X., Parker, S., Liu, Y., Graettinger, A. J., \& Forde, S. (2013). Intelligent geocoding system to locate traffic crashes. Accident Analysis \& Prevention, 50, 1034-1041.

[26] Zimmerman, D. L., Fang, X., Mazumdar, S., \& Rushton, G. (2007). Modeling the probability distribution of positional errors incurred by residential address geocoding. International Journal of Health Geographics, 6(1), 1.

[27] Hutchinson, M., \& Veenendall, B. (2005, August). Towards using intelligence to move from geocoding to geolocating. In Proceedings of the 7th Annual URISA GIS in Addressing Con-ference.

[28] Farvacque-Vitkovic, C., Godin, L., Leroux, H., Chavez, R., \& Verdet, F. (2005). Street address-ing and the management of cities. The World Bank.

[29] Malaainine, M., Slaoui, L., Rhinane, H., \& Baidder, L. (2010, May). Méthode de Saisie en Masse des Points d'Adresses Géolocalisés de la Grande Ville de Casablanca. In First International Congress on GIS and Land management (SIGGT 2010), Casablanca (p. 101).

[30] Goldberg, D. W. (2009). A Geocoding Best Practices Guide, The North American Association of Central Cancer Registries. http://www. naaccr. org/filesystem/pdf/Geocoding_Best_Practices. pdf.

[31] Karimi, H. A., Sharker, M. H., \& Roongpiboonsopit, D. (2011). Geocoding recommender: an algorithm to recommend optimal online geocoding services for applications. Transactions in GIS, 15(6), 869886.

[32] Hutchinson, M. J. (2010). Developing an agent-based framework for intelligent ge-ocoding (Doctoral dissertation, Curtin University).

[33] Lee, J. (2004, October). 3D GIS for geo-coding human activity in microscale urban environ-ments. In International Conference on Geographic Information Science (pp. 162-178). Spring-er, Berlin, Heidelberg.

[34] Davis Jr, C. A., Fonseca, F. T., \& Borges, K. A. (2003, October). A Flexible Addressing System for Approximate Geocoding. In GeoInfo.

[35] Cayo, M. R., \& Talbot, T. O. (2003). Positional error in automated geocoding of residential ad-dresses. International journal of health geographics, 2(1), 10.

[36] Bakshi, R., Knoblock, C. A., \& Thakkar, S. (2004, November). Exploiting online sources to ac-curately geocode addresses. In Proceedings of the 12th annual ACM international workshop on Geographic information systems (pp. 194-203).

[37] Wu, J., Funk, T. H., Lurmann, F. W., \& Winer, A. M. (2005). Improving spatial accuracy of roadway networks and geocoded addresses. Transactions in GIS, 9(4), 585-601. 